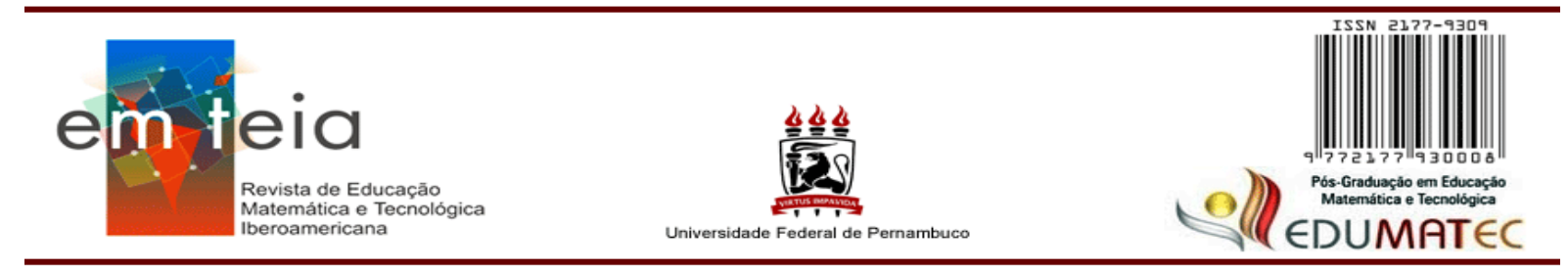

\title{
ASPECTOS DA FORMAÇÃO DE PROFESSORES QUE EMERGEM A PARTIR DA LEITURA DE UM CADERNO ESCOLAR (1933)
}

\author{
Rosilda dos Santos Morais \\ Doutora em Educação Matemática \\ Universidade Federal de São Paulo/UNIFESP, Diadema \\ Membro do Grupo de Pesquisa História da Educação Matemática no Brasil (GHEMAT). \\ rosildamorais7@gmail.com
}

Isso são ruídos. Mas há algo aqui que é mais terrível: o silêncio. Eu acredito que no decorrer de grandes incêndios ele deve chegar, assim, às vezes, em momentos de tensão extrema: os jatos de água retrocedem, os bombeiros não estão mais na escada, ninguém se move. Sem barulho, uma onda negra avança, no alto, e uma grande parede por detrás de onde o fogo brotava, dobra-se silenciosamente. Todo mundo está imóvel e espera, de ombros elevados, rostos contraídos sobre os olhos, um terrivel golpe. Tal é o silêncio aqui ${ }^{l}$.

(RILKE, 1926, p. 3-4, trad. livre).

\section{RESUMO}

O presente texto é resultado da análise de um caderno escolar de um curso de formação de professores, da cidade de Muzambinho, Minas Gerais, Brasil, do ano de 1933. O olhar da autora se voltou a aspectos da formação de professores que emergiram a partir da leitura do caderno. Para a análise consideraram-se referenciais que problematizam os cadernos escolares como fontes de pesquisa, como Viñao (2008), Hébrard (2001), Mignot (2008); aqueles que problematizam os saberes institucionalizados na formação de professores, como Hofstetter e Schneuwly (2017), Valente (2017); bem como Foucault (1987), tendo em conta que os cadernos escolares podem ser pensados como elementos disciplinadores. A investigação foi orientada pela seguinte interrogação: "Que elementos emergem de cadernos escolares que podem ser indicativos de processos e dinâmicas da formação de professores?". Os resultados indicaram diferentes aspectos lidos no caderno, quais sejam, os relativos aos saberes específicos, objetivados por meio dos conteúdos do ensino e da formação, aqueles que constituir-se-ão em objetos de seu trabalho, como os saberes $a$ ensinar e para ensinar. De outra parte, identificaram-se elementos de disciplinação da formação de professores a partir de indícios do caderno analisado.

Palavras-chave: aritmética. Disciplinação. História da educação matemática. Escolas normais. Saberes matemáticos.

\footnotetext{
${ }^{1}$ Cela, ce sont les bruits. Mais il y a quelque chose ici qui est plus terrible: le silence. Je crois qu'au cours de grands incendies il doit arriver, ainsi, parfois, un instant de tension extrême: les jets d'eau retombent, les pompiers ne moment plus à l'échelle, personne ne bouge. Sans bruit, une corniche noire s'avance, là-haut, et un grand mur derrière lequel le feu jaillit s'incline sans bruit. Tout le monde est immobile et attend, les épaules levées, le visage contracté sur les yeux, le terrible coup. Tel est ici le silence (RILKE, 1926, p. 3-4).
} 


\begin{abstract}
The present text is the result of the analysis of a notebook of a teacher training course, from the city of Muzambinho, Minas Gerais, Brazil, in the year 1933. The author's perspective focus in aspects of teacher training that emerged from reading of the notebook. For the analysis, it was considered references that problematize the notebook as research sources, such as Viñao (2008), Hébrard (2001), Mignot (2008), those who problematize institutionalized knowledge in teacher training, such as Hofstetter and Schneuwly (2017), Valente (2017), and Michel Foucault (1987), considering that notebook can be thought of as disciplining elements. The research was guided by the following question: "What elements emerge from notebooks that can be indicative of processes and dynamics of teacher education?". The results indicated different aspects read in the notebook, namely those related to specific knowledge, objectified through the contents of teaching and training, those that will constitute objects of their work, such as the know how to teach and know to teach. On the other hand, elements of the discipline of teacher training were identified based on evidence from the notebook analyzed.
\end{abstract}

Keywords: arithmetic, disciplining, history of mathematical education, normal schools, mathematical knowledge.

\title{
Situando este texto
}

A iniciativa por produzir este texto ${ }^{2}$ se deu a partir do interesse da autora em investigar cadernos escolares de "outros tempos". Um movimento do Grupo de Pesquisa em História da Educação Matemática (GHEMAT), Brasil, contribuiu para que esse interesse ganhasse forma. Por meio de uma chamada nacional, a partir de 2016, o Grupo vem inventariando e tornando público, no Repositório Institucional da Universidade Federal de Santa Catarina ${ }^{3}$, cadernos escolares antigos. Até o momento da escrita deste texto o número de cadernos do referido Repositório ultrapassava duzentos, revelando-se, este, em um espaço singular de armazenamento de documentos que tem se apresentado como um lócus para a pesquisa em história da educação, história da educação matemática, “especialistas em currículo e formação de professores e os psicólogos, entre outros, preocupados em examinar o vivido na sala de aula" (MIGNOT, 2008, p. 7), fato que tem colocado os cadernos escolares na cena dos objetos ou fontes para pesquisas que se voltam exclusivamente à análise desses documentos.

Para a escrita deste texto foram considerados cadernos que pertenceram a professores ou a professores em formação no intervalo de tempo de 1900 a 1940 por ser esse um recorte temporal de interesse desta autora em vista de outro projeto de pesquisa, sob sua responsabilidade, em andamento. A análise de cadernos escolares produzidos em intervalo de tempo concomitante ao de outras pesquisas de mesma autoria pode contribuir para que, no

\footnotetext{
${ }^{2}$ Este texto é uma composição e aprofundamento do trabalho apresentado pela autora nos anais do "XV Seminário Temático: Cadernos escolares de alunos e professores e a História da educação matemática, 18901990" (MORAIS, 2017) realizado na Universidade Federal de Pelotas, Pelotas, em abril de 2017.

${ }^{3}$ Disponível em: https://repositorio.ufsc.br/handle/123456789/160300 Acesso em: 04 jul. 2017.
} 
movimento de tessitura da teia que configura a pesquisa acadêmica, novos contornos possam ser delineados.

Cada um dos cadernos constantes do Repositório possui uma ficha meta dados. Nela, orientada pela interrogação: "Que elementos emergem de cadernos escolares que podem ser indicativos de processos e dinâmicas da formação de professores?", buscou-se pela palavra Aritmética (ou Matemática) no título, no resumo, pelo autor do caderno, bem como se ele pertencia a professores ou a professores em formação. Por certo que nessa classificação outros cadernos poderiam estar sendo desconsiderados no período em análise, tendo em vista não trazerem as informações no título ou no resumo. Mas, como toda classificação implica em delimitação, assumiu-se o risco mantendo-se, assim, em aberto para novas classificações, se necessário fosse.

Para fins de organização, este texto apresenta ensaios da literatura acerca da potencialidade dos cadernos escolares como fontes de pesquisa; na sequência, o caderno investigado ganha a cena; e, por fim, são problematizados alguns indícios que dizem de aspectos da formação de professores, todos os quais emergiram do caderno.

\section{Os cadernos escolares: o que possibilitam eles à historiografia?}

Jean Hébrard (2001) afirma que as fontes documentais existentes não nos permitem estabelecer uma verdadeira história do caderno escolar, mas que foi no primeiro terço do século XIX que houve sua generalização de modo a produzir um efeito importante na evolução da alfabetização escolar. Esse pesquisador afirma que o estudo de cadernos escolares aparece "como um exemplo privilegiado da aplicação dos métodos da bibliografia material aos objetivos manuscritos portadores e escrituras ordinárias" (2001, p. 115) e que o caderno é certamente um testemunho precioso do que pode ter sido e ainda é o trabalho escolar de escrita. Hébrard (2001) diz ainda que o advento das grandes exposições internacionais pode ter contribuído para que após os anos de 1860 cadernos escolares passassem a ser conservados, pois constituíam-se em parte dos objetos que eram expostos nesses eventos com o intuito de mostrar o que de educação cada país vinha realizando. Nessa esteira, falando sobre a Exposição de 1900 em Paris, Henry Lemonnier, professor da Faculdade de Letras de Paris e autor do relatório sobre o ensino secundário na referida exposição, ressalta o valor representativo de uma "cópia" dos estudantes ou de uma soma das observações, da reflexão, da experiência, todas essas encerradas numa brochura pedagógica (MATASCI, 2015), os cadernos escolares. 
O pesquisador Antônio Viñao (2008, p. 17) afirma que "constatar apenas que os cadernos escolares vêm sendo nos últimos anos uma fonte-objeto de especial estudo e atenção desde a história da educação oculta a diversidade de perspectivas e interesses, geralmente complementares, de onde a dita atenção se originou". Para esse pesquisador, os cadernos escolares "não são apenas um produto da atividade realizada nas salas de aula [...] e da cultura escolar, mas também uma fonte que fornece informação - por meio, sobretudo, de redações e composições escritas - da realidade material da escola e do que nela se faz" (VIÑAO, 2008, p. 16).

Ainda se pode ler em Viñao (2008) que os cadernos escolares possibilitam estudar diferentes ideologias e valores do meio escolar, pois eles possibilitam uma aproximação mais fidedigna à realidade e às práticas escolares, e, além disso, reformas e inovações educativas podem ser identificadas ao analisar esse documento. Sobre esse último aspecto, o pesquisador destaca que

Se um dos problemas mais característicos da implantação e difusão das reformas e inovações é a defasagem ou distância existente entre as propostas teóricas, a legalidade e as práticas docentes e discentes, os cadernos escolares constituem uma fonte valiosa na hora de conhecer e analisar de um modo bastante confiável tanto os processos de implantação e difusão mencionados como os de hibridação, adaptação, acomodação, rechaço ou aceitação que costumam acompanhá-los (VIÑAO, 2002, p. 82-120 apud VIÑAO, 2008, p. 17).

Valente (2017, p. 2), utilizando cadernos escolares, problematiza a relação existente entre "saberes de formação dos professores e aqueles professados pelos docentes em seu ofício profissional. As relações entre formação e docência e, em particular, aquelas que têm em conta os saberes matemáticos”. Esse pesquisador, apoiado em Bernard Charlot, centra sua atenção nas "relações com saber-objeto", isto é, "um saber em si mesmo, na medida em que ele é 'objetivado', isto é, apresentado como um objeto intelectual, como referente de conteúdo de pensamento" (CHARLOT, 1997, p. 77 apud VALENTE, 2017, p. 2). Valente (2017, p. 2) diz ainda que "a matemática que o professor mobiliza no ensino não pode ser identificada com a matemática da formação que o professorado recebe" e que, por essa razão, cabem investigações sobre os usos que docentes fazem dessa formação, lida na relação que esses profissionais estabelecem com o saber. Em suma, este pesquisador ressalta que se faz importante analisar as relações com o saber do professor que ensina matemática.

A ida aos cadernos pode ser uma via pela qual se pode problematizar tais questões colocadas pela literatura. 


\section{O caderno do $1^{\circ}$ ano do curso de adaptação de Márcia Moreira Sousa}

Da pesquisa no Repositório, no período de 1900 a 1940, identificamos apenas um caderno considerando a classificação apresentada, isto é, que trazia a palavra Aritmética (ou Matemática) no título ou na ficha meta dados cuja autoria fosse de professores ou de professores em formação. Consta na ficha meta dados o nome de Márcia Moreira Sousa, uma estudante do primeiro ano de adaptação ${ }^{4}$ de um curso de normalistas, na cidade de Muzambinho, estado de Minas Gerais, ano de 1933. Na verdade, trata-se de um cadernodiário no qual Sousa descrevia o que se passava em suas aulas nos mais diferentes componentes curriculares, ou cadeiras, como ela enunciou. Por ser ele um caderno de estudante em curso de formação de professores, considerou-se a análise desse documento, que se constituiu em fonte desta pesquisa.

$\mathrm{Na}$ ficha meta dados constam-se as seguintes informações: "Cadernos de classe (português, aritmética, matemática, ciências, geografia, história do brasil, francês, desenho)", bem como são descritas as características físicas do caderno, referindo-se à capa, do tipo brochura, preta e vermelha, sem cobertura. Há 93 páginas, todas preenchidas, pautado, com dimensões $16,5 \mathrm{~cm}$ x $23,5 \mathrm{~cm}$. O exemplar físico pertence ao acervo de COMPASSO Distrito Federal (DF), diz o documento.

Acredita-se que tal ficha tenha como propósito dar a ver ao leitor a materialidade do documento tendo em vista sua natureza, objeto digital. Demais informações são encontradas ao acessar o arquivo, constante também no referido Repositório, passo seguinte desta autora à análise da ficha meta dados.

De um "livro branco" a um texto escrito, um ano se passou, o ano de 1933...

Sousa preenche as folhas brancas de seu caderno, na verdade um "diário" de uma professora em formação no $1^{\circ}$ ano do curso de adaptação, durante o ano letivo de 1933. Considerando o período estipulado nesta pesquisa, o caderno de Souza foi o único que atendia

\footnotetext{
${ }^{4}$ Sobre esse tema, Leonor Maria Tanuri (2000) destaca que no ciclo de ideias e princípios escolanovistas que atravessou a educação brasileira nos idos dos anos de 1920/1930, um conjunto de normas didático pedagógicas, que inspiraram a introdução de novas disciplinas de formação de professores, foi produzido, além de uma diferenciação nas modalidades de escola. Foi o caso, por exemplo, do Estado de Minas Gerais, cuja educação foi organizada, em 1927, em "três níveis: 1) Escolas Normais de Segundo Grau (somente oficiais), oferecendo a seguinte formação: Curso de Adaptação, complementar ao primário (dois anos); Curso Preparatório, de cultura geral (três anos) e Curso de Aplicação, de caráter essencialmente profissional (dois anos); 2) Escolas Normais de Primeiro Grau (oficiais e particulares), oferecendo o Curso de Adaptação (dois anos) e o Curso Normal com três anos de duração, sendo três de cultura geral e um de formação profissional; 3) Cursos Normais Rurais, com duração de apenas dois anos, funcionando junto aos grupos escolares, e oferecendo apenas um aprofundamento das matérias do ensino primário, acrescido de atividades de prática de ensino" (p. 14-15).
} 
à classificação inicialmente esboçada, como antes citado. Era preciso, então, romper com $o$ silêncio do caderno, silêncio quebrado ao abri-lo.... Abrindo-o, que ruídos emergem?

\section{Uma leitura do caderno de Souza}

Conforme a ficha meta dados, trata-se de um caderno de capa dura, brochura, nas cores preto e vermelho. Em sua contracapa, figura 1, Sousa esboça o horário das aulas, no qual constam três aulas semanais de Aritmética (a qual ela nomeia de "cadeira"), às segundas, quartas e sextas feiras, das $8 \mathrm{~h}$ às $8 \mathrm{~h} 55 \mathrm{~min}$. Todas as manhãs eram preenchidas com aulas, inclusive aos sábados, com cadeiras de: Português, Francês, Aritmética, Educação Física, Desenho, Trabalho, Ciências, Geografia ${ }^{5}$ e Música, como mostra a Figura 1 a seguir:

FIGURA 1 - contracapa do caderno Márcia Moreira Sousa $(1933)^{6}$

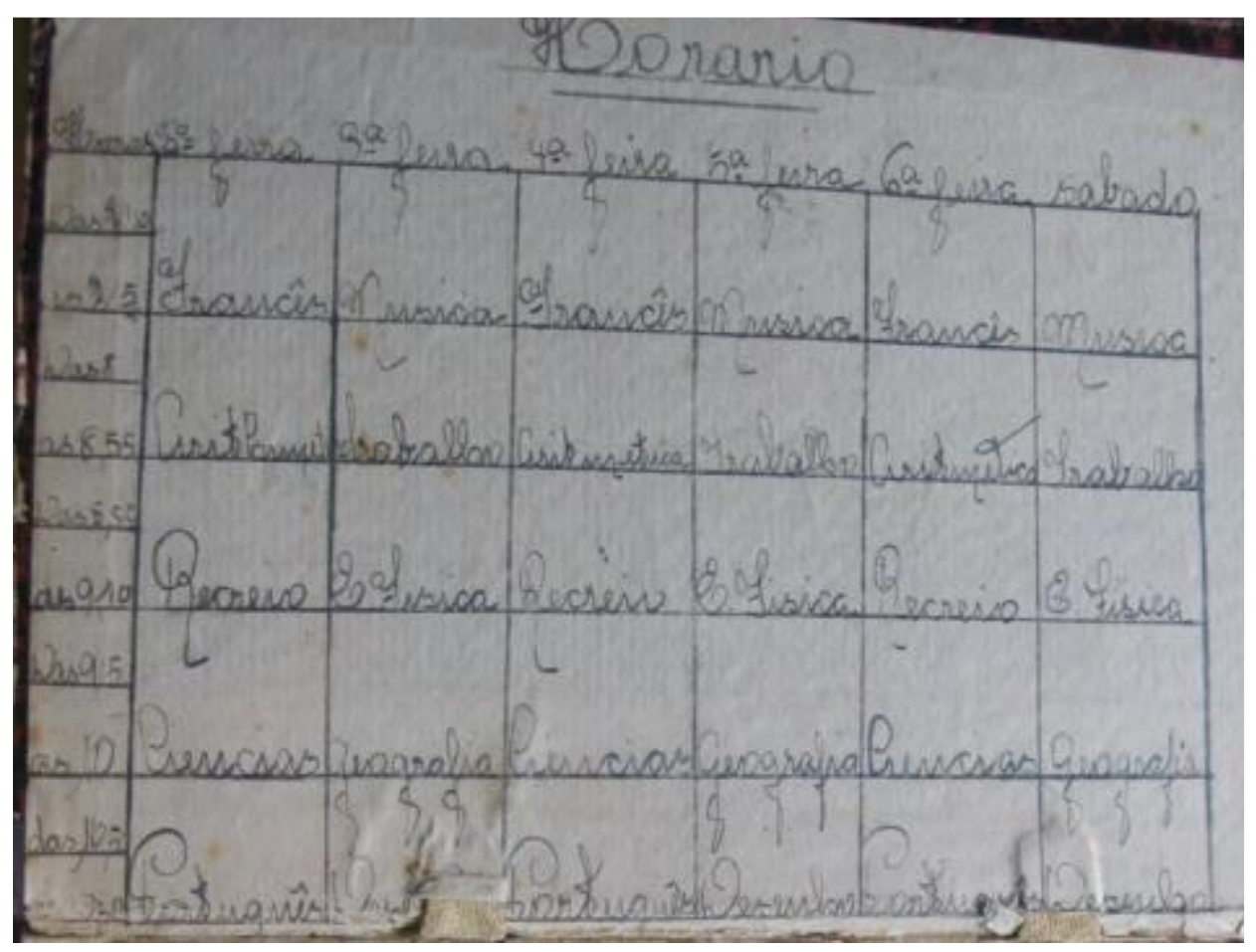

Disponível em: https://repositorio.ufsc.br/xmlui/handle/123456789/166685. Acesso em: 24 jun. 2017.

A primeira parte do caderno é destinada à cadeira de Português e a segunda à de Aritmética. As demais cadeiras vêm na sequência. Considerando os limites deste texto,

\footnotetext{
${ }^{5}$ A investigação no caderno revelou que a cadeira de Geografia era, na verdade de "Geografia e História do Brasil".

${ }^{6}$ Disponível em: https://repositorio.ufsc.br/xmlui/handle/123456789/166685 Acesso em: 24 jun. 2017.
} 
colocar-se-á ênfase à cadeira de Aritmética, ministrada pela "Professora D. Maria Carina de Almeida", conforme Sousa se referia à sua professora.

A organização do caderno de Sousa apresentava a seguinte configuração: dia do mês em uma coluna e "pontos" (temas) a tratar em uma outra, na sequência da primeira, conforme Figura 2 a seguir:

FIGURA 2 - primeira página do caderno de Márcia Moreira Souza

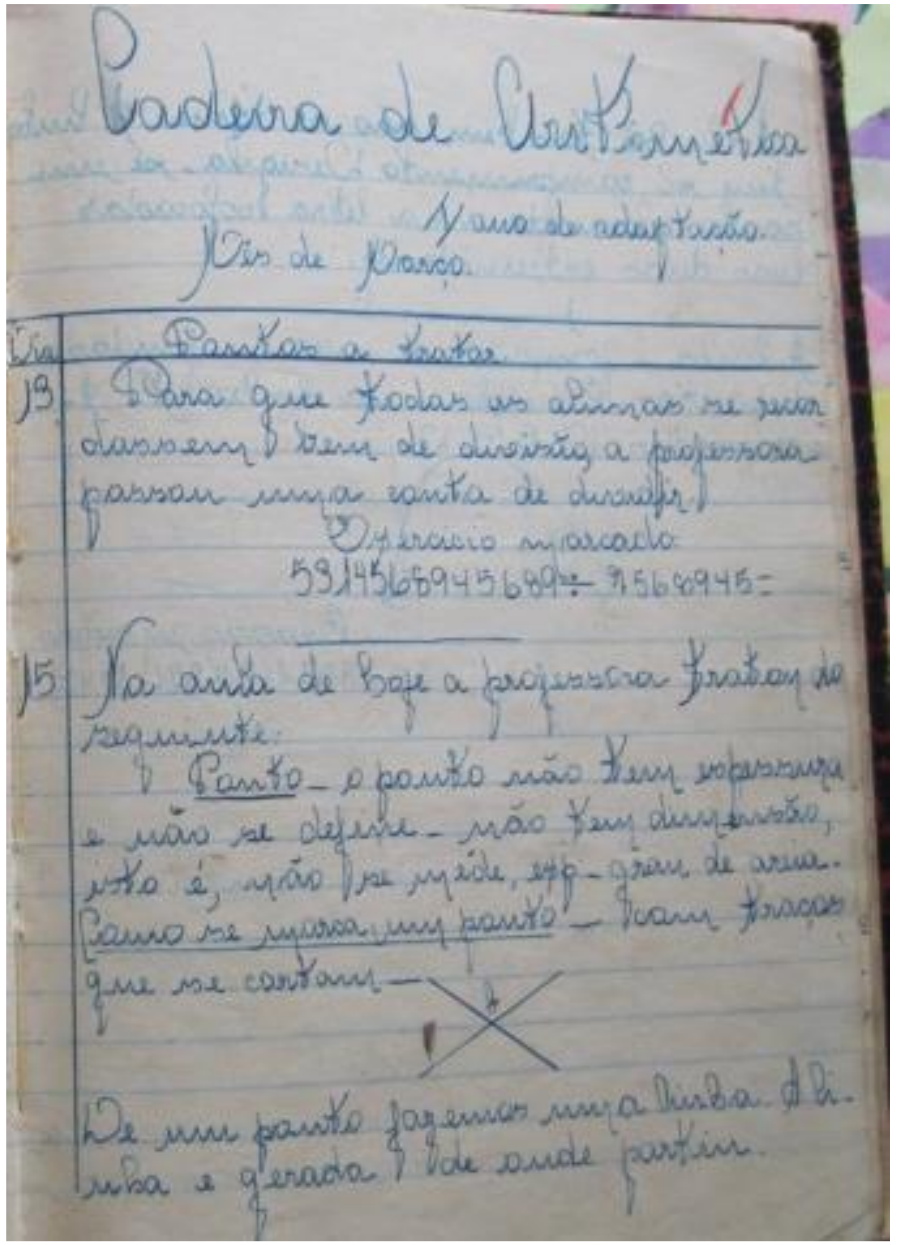

${ }^{1}$ Disponível em: https://repositorio.ufsc.br/xmlui/handle/123456789/166685. Acesso em: 24 jun. 2017.

Logo de início, no dia 13 de março de 1933, uma frase diz do sexo dos matriculados nessa cadeira (Figura 2), o feminino: "Para que todas as alunas se recordassem bem da divisão, a professora passa uma conta de dividir. Exercício marcado: 5314568945689 7568945" (SOUSA, 1933, s/p., grifo nosso).

Embora a cadeira seja de Aritmética, na aula do dia 15 de março foram tratados, também, temas de Geometria, aliás, até o mês de junho essa foi a regra. Inicialmente discutiram-se noções de "ponto e linha", bem como um "exercício marcado" envolvendo 


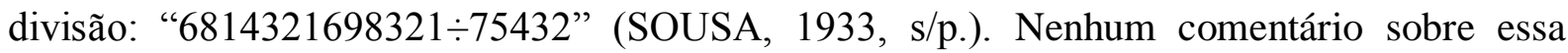
operação foi identificado no caderno de Sousa.

Na aula seguinte, 17 de março de 1933, as notas no caderno de Sousa indicam definições de reta (linha reta, semi-reta, reta suporte, semi-reta oposta e segmento de reta) e novos "exercícios marcados", mas, desta vez, envolvendo as quatro operações elementares, isto é, adição, subtração, multiplicação e divisão.

Dia 20 de março Sousa anota em seu caderno que a aula foi iniciada com a professora arguindo as alunas sobre os temas tratados na aula anterior, além de explicar novos temas da Geometria, tais como segmentos colineares, linha poligonal ou quebrada, dentre outros. As aulas que sucederam a essa tiveram suas notas no caderno bastante reduzidas, com explicações de ordem geral que indicam terem continuado a discutir Geometria até a primeira avaliação, que ocorreu no final de março de 1933.

O mês de abril do mesmo ano é iniciado, e com ele as notas de aula indicam que conteúdos de Geometria imperavam nas aulas de Aritmética. Os conteúdos abordados ao longo do mês nessa cadeira compreenderam: superfície, corpo sólido ou geométrico, volume, polígonos e paralelepípedo. Além dos temas de Geometria citados, com respeito à Aritmética, nas notas de aula identificaram-se, no dia 10 de abril, dois "exercícios marcados": um que requeria o cálculo de uma extensa expressão numérica envolvendo as operações de subtração, multiplicação e divisão, e um segundo que, na verdade, se tratava de um problema de Aritmética, com os seguintes dizeres: "Um negociante comprou 2383 carneiros, vendeu dias depois 652 e, mais tarde, dois terços do resto. Quantos ficaram?" (SOUZA, 1933, s/p). O problema proposto, ao que parece, se configurava como um fim em si mesmo, isto é, com o objetivo único de ter as operações elementares trabalhadas.

Nos demais dias do mês de abril, nas aulas de Aritmética, além de expressões numéricas foram propostas atividades que requeriam e escrita de números por extenso.

Sousa destaca, ainda, em suas notas que a professora Maria Carina tinha como prática arguir as alunas sobre temas tratados em sala. Essa prática era constante no decorrer do período letivo. Outros registros no caderno apontam que ao final de cada mês uma prova era aplicada, bem como todas as atividades das alunas, futuras professoras, eram corrigidas pela professora Maria Carina com lápis de colorir na cor vermelho. Essas correções evidenciam aspectos, no mínimo, interessantes para a pesquisa historiográfica, alguns dos quais serão aqui trazidos.

As correções da professora Maria Carina até o encerramento do mês de junho eram de duas naturezas, atenção à norma culta da língua, acentuando sempre a palavra Aritmética, por 
exemplo, e orientações no sentido de uma melhor organização do caderno. No dia 03 de julho de 1933, possivelmente a primeira aula do segundo semestre letivo, à frente da expressão “cadeira de Aritmética" a professora Maria Carina escreve "Matemática” com lápis colorido vermelho, o mesmo utilizado nas correções. A palavra Aritmética é riscada. Não se pôde identificar nas notas de aula o porquê da mudança de nome da cadeira, a qual Sousa leva um tempo para se adaptar, pois até o mês de setembro a professora Maria Carina segue repetindo a mesma prática, ora sublinhando a palavra Aritmética, ora colocando-a entre parênteses indicando a necessidade de alteração no nome da cadeira, de "cadeira de Aritmética" para “cadeira de Matemática”. Em setembro Sousa passa a escrever "cadeira de matemática”. Essa confusão por parte da aluna é identificada também nas notas de aula, pois quando ela deveria, por exemplo, escrever "problema de Matemática", escrevia "problema de Aritmética", enganos esses também corrigidos pela professora. Recuperando uma frase de Viñao (2008) apresentada no início deste texto, quando o pesquisador diz que os cadernos escolares possibilitam identificar reformas e inovações educativas, a mudança de nome da cadeira de Aritmética para Matemática pode caracterizar uma dessas reformas, não só pela mudança de nome em si, mas pela identificação de uma nova metodologia de trabalho adotada pela professora para a cadeira de Matemática. Entretanto, caberia uma investigação mais alargada na regulamentação do referido curso à época do caderno de Sousa, atividade que não será possível de ser realizada neste texto.

Sobre a nova metodologia de trabalho na cadeira de Matemática, as notas de aula de Sousa indicam que tal cadeira se voltava quase que exclusivamente ao ensino de Aritmética com ênfase em processos e não apenas em resultados, como identificado a partir dos extensos cálculos de operações elementares por meio de expressões numéricas, por exemplo. Nessa nova configuração de curso, em vez de apenas efetuarem divisões, multiplicações ou de calcularem os valores de longas expressões numéricas, como se estivesse a professora interessada em verificar a posse daquele que era o objeto de trabalho do futuro professor, os saberes $a$ ensinar. Nesse segundo semestre a metodologia adotada pareceu seguir uma outra lógica, ou seja, consistia de "ensinar saberes no amplo sentido, tendo em conta o auxílio de saberes, de enunciados comunicáveis e socialmente reconhecidos, ou dizendo de outro modo, tendo ajuda de saberes didatizados" (HOFSTETTER; SCHNEUWLY, 2017, p. 133). Tais saberes constituem ferramentas de trabalho do professor, neste caso saberes para formar ou saberes para ensinar, ou seja, saberes sobre "o objeto" do trabalho de ensino e de formação: 
Somar é reunir o valor de dois ou mais números em um só. Os números que se somam chamam-se parcelas e o resultado da operação chama-se soma ou total. $\mathrm{O}$ sinal + escrito entre 2 números mostra que estes dois números devem se somar: $2+5=7$. A ordem das parcelas não altera uma soma. Todas as parcelas de uma soma devem ser quantidades da mesma espécie. Não podemos reunir em um só número quantidades de espécies diferentes; 2 penas, 2 lápis não são 5 penas nem 5 lápis. Só podemos somar quantidades homogêneas. A soma é sempre da mesma espécie que as parcelas (SOUSA, 1933, s/p.).

As notas de aula de Sousa indicam que o ensino de regras para a soma também era evidenciado, como no excerto a seguir:

\begin{abstract}
Regra - Para se somar escrevemos três (as) parcelas umas debaixo das outras, de sortes que as unidades da mesma ordem fiquem em coluna. Então diremos: 2 e 8 são dez que escrevemos "0" debaixo das unidades, levaremos um para somar com as dezenas; diremos 1 e 5 são 6 e 2 são 8 que escrevemos debaixo das dezenas. Passando às centenas, continuaremos 2 e 3 são 5 que escrevemos debaixo das centenas. O número será pois 580 (Ibid.; sic.)
\end{abstract}

Na sequência Sousa discute como se faz para tirar a prova real da operação citada, fala sobre as propriedades da adição, diz que a soma é uma operação unívoca, associativa e comutativa e, por fim, aparece uma nota dizendo: "exercício marcado", o qual consiste de um problema de aritmética: “Alvaro guarda tantos nikeis de $400(\$)$, quantos 1000 (\$) recebe por mês. Pede-se a quantia que conseguiu reunir Alvaro no fim do mês de setembro se faltou 5 dias ao trabalho, sabendo-se que guarda 180000 (\$) por mês" (Ibid.; sic). O que Sousa nomeia, aqui, de "exercício marcado", em algumas notas ela muda esse título para "exercício escrito". Novamente não há nas notas de aula indicativos relativos à problematização desse problema, o que pode ser um indício de que ele se constituía um fim em si mesmo, tal como já exposto neste texto.

Avançando a investigação do caderno de Sousa, no dia 19 de agosto de 1933 identifica-se o que ela nomeou de "aula especial". Nela o tema tratado foi "posição relativa de retas e planos", ou seja, temas de Geometria. Ainda nesse mês, no dia 26, uma outra "aula especial" foi ministrada, cujo tema trabalhado foi "ângulos" e "tipos de ângulos". Em setembro de 1933 houve mais duas "aulas especiais" de Geometria. A partir de então, elas não foram mais identificadas nas notas de aula. Assim, no segundo semestre de 1933, as aulas de Geometria se resumiram a quatro encontros. Nos meses de outubro e novembro, a expressão "aula especial" passou a ser utilizada para tratar do estudo de frações.

Um caderno não se limita a um espaço no qual são esboçadas percepções, sínteses, comentários relativos ao componente curricular ao qual ele se destina. Já foi dito neste texto 
sobre a organização do caderno de Sousa, cujos temas foram dispostos em colunas, as quais contêm dia do mês e conteúdos trabalhados. Outro aspecto que se identificou no caderno analisado foi o relativo à concepção de formação de professores ali expressa. Cite-se, por exemplo, uma nota do dia 03 de abril:

“Enquanto a professora pôsz [correção da professora] visto nos diários fizemos o seguinte exercício” (notas aula Sousa, 1933, s/p.), o qual segue na Figura 3:

FIGURA 3 - caderno de Márcia Moreira Souza (s/p.)

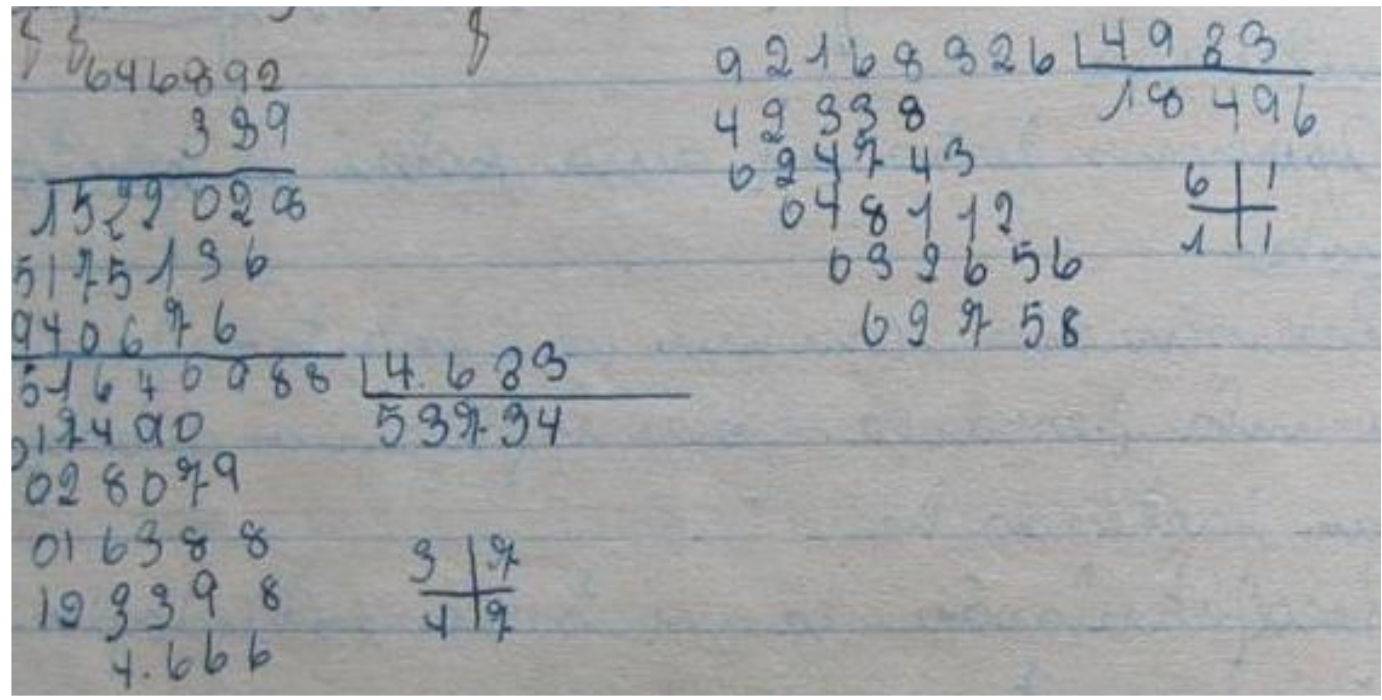

Disponível em: https://repositorio.ufsc.br/xmlui/handle/123456789/166685. Acesso em: 24 jun. 2017

Além do imediatamente exposto, identifica-se que essa era uma constante no curso de formação de professores de Sousa, ou seja, o ato de ocupar as alunas era uma sofisticação daquilo que pode ser considerado formas gerais de dominação, de doutrinação do corpo. Essas, entretanto, diferem daquelas utilizadas em tempos de escravidão, como afirma Foucault (1987). Para esse pesquisador, no decorrer dos séculos XVII e XVIII as disciplinas se tornaram fórmulas gerais de dominação, pois, diferentes da escravidão, "não se fundamentam numa relação de apropriação do corpo; é até elegância da disciplina dispensar essa relação custosa e violenta obtendo efeitos de utilidade pelo menos igualmente grandes" (p. 110). O caderno de Sousa traz muitos indícios de tais elementos, como se pode identificar na frase a seguir:

"Enquanto a professora corrigia os exercícios feitos pelas alunas em aula anterior, praticávamos em caligrafia” (SOUSA, 1933, s/p.) 
Outro aspecto que convém destacar diz respeito à metodologia adotada pela professora. No segundo semestre, na cadeira de Matemática, identificam-se dinâmicas e processos da formação de professores que destoam sobremaneira da trabalhada no primeiro semestre, com a mesma turma e mesma professora. É o caso, por exemplo, das operações elementares. No primeiro semestre, as estudantes, futuras professoras, despendiam tempo relativamente grande calculando expressões numéricas, operações com números de magnitude elevada sem que fossem, ao menos no que se pôde identificar no caderno, problematizadas as etapas de resolução de tais operações. Essa constatação possibilita caracterizar a formação de professores vivenciada por Sousa sob duas naturezas: (1) no primeiro semestre, com respeito ao ensino de Aritmética, as notas do caderno indicam uma metodologia que visava identificar a posse dos saberes $a$ ensinar, de uma matemática $a$ ensinar ${ }^{7}$, bem como se pôde identificar elementos de disciplinação ${ }^{8}$ da formação de professores; (2) no segundo semestre, com a mudança de nome da cadeira, pôde-se identificar uma metodologia que se voltava mais aos saberes para ensinar, uma matemática para ensinar, seguida dos mesmos elementos de disciplinação. Sobre tais saberes, Hofstetter e Schneuwly (2017, p. 134) destacam que os saberes para ensinar são as ferramentas de trabalho do professor,

Trata-se principalmente de saberes sobre "o objeto" do trabalho de ensino e de formação (sobre os saberes a ensinar e sobre o aluno, o adulto, seus conhecimentos, seu desenvolvimento, as maneiras de aprender etc.), sobre as práticas de ensino (métodos, procedimentos, dispositivos, escolha dos saberes $a$ ensinar, modalidades de organização e de gestão) e sobre a instituição que define o seu campo de atividade profissional (planos de estudos, instruções, finalidades, estruturas administrativas e políticas etc.).

Em suma, o que se pode ler a partir das linhas imediatamente anteriores indica que o tratamento dado à formação de professores, no que tange à cadeira de Matemática, no segundo semestre do curso de formação de Sousa aponta para uma formação que mobiliza tanto os saberes a ensinar quanto os saberes para ensinar, além de elementos, como já evidenciado, de naturezas subjetivas, como os de disciplinação. Não se quer, com isso, reduzir

\footnotetext{
${ }^{7}$ Entende-se neste texto a expressão "matemática $a$ ensinar" como aquela advinda de um campo matemático. No caso do caderno de Sousa pode-se dizer que tais conteúdos matemáticos, por exemplo aqueles da escola básica os quais ela deveria mobilizar para realizar as operações pedidas pela professora, têm caráter de um saber de cultura geral. Trata-se de uma matemática que deve participar da formação de todo cidadão escolarizado (VALENTE, 2017). Para saber mais sobre os temas "saberes $a$ ensinar", "saberes para ensinar", "matemática para ensinar" e "matemática $a$ ensinar" indica-se Hofstetter e Valente (2017) e Bertini, Morais, Valente (2017).

8 "Processo pelo qual os indivíduos se apropriam, ou são sujeitos à disciplina, aqui em todos os sentidos do termo" (HOFSTETTER; SCHNEUWLY, 2017, p. 24).
} 
a formação de professores problematizada a partir do caderno de Sousa aos elementos aqui enunciados haja vista a complexidade inerente a todo processo de formação. Todavia, "o caderno fala" e por meio dessa "fala" pode-se fazer leituras da formação de professores, da formação vivenciada por Sousa.

Além dos saberes matemáticos da formação de professores, o caderno de Sousa revela outros elementos dessa formação que transcendem aos saberes específicos, tais como os anteriormente citados por Hofstetter e Schneuwly (2017). É o caso, por exemplo, do poder disciplinar do caderno, como também de uma formação disciplinar de professores. A organização do conteúdo pela aluna, disposto em colunas, os quais eram sistematicamente corrigidos pela professora, como também pelas marcas inscritas no caderno; os exaustivos cálculos de aritmética, bem como as próprias notas de aula deixadas pela aluna, as quais indicavam que enquanto a professora se voltava à realização de atividades técnicas de seu ofício docente, como corrigir cadernos, elas eram ocupadas com tarefas que pareciam ter o objetivo único de ocupá-las, discipliná-las, caracterizam a formação "disciplinar" de professores.

A organização do caderno, a disposição dos conteúdos, o poder de síntese, a supressão de erros, exercícios propostos para, ao que parece, ocupar as alunas enquanto a professora realiza outras atividades constituem-se em elementos que caracterizam saberes subjetivos da formação de professores que, de alguma forma, podem ser lidos no tocante aos saberes disciplinadores de tal formação; disciplinador, pois "implica numa coerção ininterrupta, constante, que vela sobre os processos da atividade mais do que sobre o resultado e se exerce de acordo com uma codificação que esquadrinha ao máximo o tempo, o espaço, os movimentos" (FOUCAULT, 1987, p. 110).

\section{Considerações finais}

Este texto teve início com uma epígrafe de Rainer Maria Rilke, extraída do livro Les cahiers de Malte Laurids Brigge, na qual se falou sobre ruídos, silêncio... em outro momento se interrogou, neste texto, “O que permitem os cadernos escolares à historiografia?”. Qualquer tentativa de encerrar este texto que não seja abrindo novas possibilidades de escrita seria fragilizá-lo... Assim, na tentativa de responder não à questão que mobilizou esta pesquisa, pois elementos deixados nas páginas até aqui apresentadas parecem ter dado conta disso, mas a que agora se apresenta: “Os cadernos escolares, o que permitem eles à historiografia?”. Uma possível resposta seria: podem, eles, os cadernos escolares, romper com o silêncio, 
rompimento possível ao abrir suas páginas... Do silêncio ao ruído, ruído emanado das notas de aula... Ruído que possibilita adentrar à sala de aula, à caixa preta da escola...

\section{Referências}

CADERNO escolar de Márcia Moreira Sousa. Disponível em: https://repositorio.ufsc.br/handle/123456789/166685 Acesso em: 24 jun. 2017.

FOUCAULT, M. Vigiar e Punir: nascimento da prisão. Tradução de Raquel Ramalhete, Petrópolis, RJ: Vozes, 1987. 288p.

HÉBRARD, J. Por uma bibliografia material das escritas ordinárias - o espaço gráfico do caderno escolar (França - séculos XIX e XX). Tradução Laura Hansen. Revista Brasileira de História da Educação, n. 01, jan./jun. 2001. Disponível em: http://www.rbhe.sbhe.org.br/index.php/rbhe/article/view/277/285 Acesso em: 05 nov. 2017.

HOFSTETTER, R.; SCHNEUWLY, B. Disciplinarização e disciplinação: as ciências da educação e as didáticas das disciplinas sob análise. In: HOFSTETTER, R.; VALENTE, W. R. (Orgs.). Saberes em (trans)formação: tema central da formação de professores. São Paulo: Editora Livraria da Física, 2017. pp. 21-54.

Saberes: um tema central para as formações do ensino e da formação. In:

HOFSTETTER, R.; VALENTE, W. R. (Orgs.). Saberes em (trans)formação: tema central da formação de professores. São Paulo: Editora Livraria da Física, 2017. pp. 113-172.

MATASCI, D. L'ecole républicaine et l'étranger. Une histoire internationale des reformes scolaires em France, 1870-1914. Lyon: ENS Éditions, impr. 2015. 1 vol. (276 p.)

RILKE, R. M. Les Cahiers de Malte Laurids Brigge. Traduction de Maurice Betz. Paris: Éditions Émile-Paul Frères, 1926.

TANURI, L. M. História da formação de professores. Revista Brasileira de Educação. p. 61-193. Disponível em: http://www.scielo.br/pdf/rbedu/n14/n14a05 Acesso em: 04 jul. 2017.

VALENTE, W. R. Cadernos de Professores: da matemática para ensinar para a matemática para ensinar ensinada. Disponível em: http://xvseminariotematico.paginas.ufsc.br/files/2017/03/VALENTE_T3.pdf Acesso em: 05 ju. 2017.

VIÑAO, A. Os cadernos escolares como fonte histórica: aspectos metodológicos e historiográficos. In: Ana Chrystina; MIGNOT, Venancio (Orgs.). Cadernos à vista - escola, memória e cultura escrita. Rio de Janeiro: EdUERJ, 2008. pp. 15-33. 